University of Wollongong

Research Online

Faculty of Engineering and Information

Faculty of Engineering and Information

Sciences - Papers: Part A

Sciences

$1-1-2013$

\title{
Finite element analysis of roll bit behaviors in cold foil rolling process
}

Liang Hao

University of Wollongong, Ih421@uowmail.edu.au

Zhengyi Jiang

University of Wollongong, jiang@uow.edu.au

Dongbin Wei

University of Wollongong, dwei@uow.edu.au

Xiawei Cheng

University of Wollongong, xc979@uowmail.edu.au

Follow this and additional works at: https://ro.uow.edu.au/eispapers

Part of the Engineering Commons, and the Science and Technology Studies Commons

Research Online is the open access institutional repository for the University of Wollongong. For further information contact the UOW Library: research-pubs@uow.edu.au 


\title{
Finite element analysis of roll bit behaviors in cold foil rolling process
}

\author{
Abstract \\ To investigate roll bite behaviors in cold foil rolling process, a 2D elasto-plastic finite model is established \\ using FEM software ABAQUS. Contact pressure distribution and roll contour in roll bite are also presented, \\ which demonstrate that foil rolling process is different from conventional strip rolling process. The \\ contact area is composed of entry elastic zone, entry plastic zone, an extensive neutral zone, exit plastic \\ zone and exit elastic zone. It conforms to the results of Fleck foil rolling theory. Elastic deformation and \\ work hardening of foil in roll bite are taken into account. The effect of rolling parameters, such as friction \\ coefficient, entry thickness and reduction rate on distribution of contact pressure and vertical \\ displacement are also discussed.

\section{Keywords} \\ foil, cold, behaviors, process, bit, rolling, roll, analysis, element, finite \\ Disciplines \\ Engineering | Science and Technology Studies

\section{Publication Details} \\ Hao, L., Jiang, Z., Wei, D. \& Cheng, X. (2013). Finite element analysis of roll bit behaviors in cold foil rolling \\ process. AIP Conference Proceedings, 1532 478-483.
}




\section{AlP | Proceedings}

Finite element analysis of roll bit behaviors in cold foil rolling process

Liang Hao, Zhengyi Jiang, Dongbin Wei, and Xiawei Chen

Citation: AIP Conference Proceedings 1532, 478 (2013); doi: 10.1063/1.4806864

View online: http://dx.doi.org/10.1063/1.4806864

View Table of Contents: http://scitation.aip.org/content/aip/proceeding/aipcp/1532?ver=pdfcov

Published by the AIP Publishing 


\title{
Finite Element Analysis of Roll Bit Behaviors in Cold Foil Rolling Process
}

\author{
Liang Hao ${ }^{*}$, Zhengyi Jiang, Dongbin Wei, Xiawei Chen \\ School of Mechanical Materials and Mechatronic Engineering, University of Wollongong Australia \\ Emai:lh421@uowmail.edu.au
}

\begin{abstract}
To investigate roll bite behaviors in cold foil rolling process, a 2D elasto-plastic finite model is established using FEM software ABAQUS. Contact pressure distribution and roll contour in roll bite are also presented, which demonstrate that foil rolling process is different from conventional strip rolling process. The contact area is composed of entry elastic zone, entry plastic zone, an extensive neutral zone, exit plastic zone and exit elastic zone. It conforms to the results of Fleck foil rolling theory. Elastic deformation and work hardening of foil in roll bite are taken into account. The effect of rolling parameters, such as friction coefficient, entry thickness and reduction rate on distribution of contact pressure and vertical displacement are also discussed.
\end{abstract}

Keywords: Cold Foil Rolling, Elasto-plastic Deformation, Roll Bite Behaviors, Finite Element Method.

\section{INTRODUCTION}

Cold rolling theories of Bland and Ford are universally applied in cold strip rolling process with an assumption that arc remains a circular with enlarged radius given by Hitchcock formula and strip slips relatively with roll in the roll bite except the neutral point. However, it fails in thin strip and foil rolling process where there is significant elastic deformation of roll comparing with thickness of strip.

A theory by Fleck and Johnson in 1987 [1] simplifies 'mattress model' for deformation of roll. It suggests that the work rolls deform to a non-circular profile and no-slip region between strip and work roll exits in the roll bite. Later, Fleck etc al in 1992 [2,3] present a new theory for cold foil rolling. It assumes that plastic reduction takes place in two zones at entry and exit, which are separated by a neutral zone in which the rolls are compressed flat and there is no slip between rolls and the foil. L.C. ZHANG [4] uses the slab method in conjunction with an incremental analysis to explore the interaction between the rolls and foil. H.R. Le and M.P.F. Sutcliffe et al[5- 7] follow the approach of Fleck et al, but relax their assumption of a central flat neutral zone. An explicit equation for the contact pressure variation is obtained from sticking condition in this region. T.A.M. Langlands et al [8] apply an Inverse Hilbert Transform to solve Fleck foil rolling model. In their works above, elastic zone at entry and exit, work hardening of foil are all neglected, in addition to that, iterative non-convergence problem may occur in some cases.

In this paper, cold foil rolling process is simulated by non-linear capabilities of software package ABAQUS/Explicit code [9] to attain a deep insight in this process.

\section{FINITE ELEMENT MODEL}

Since the foil width is far greater than its thickness and geometric symmetry, an upper half model of 2D plane strain is built. Parameters of model and yield stress-strain curve of foil are shown in TABLE 1 and FIGURE 1 respectively.

TABLE (1). Model Parameters

\begin{tabular}{lll}
\hline Roll & Work roll diameter $/ \mathrm{mm}$ & 260 \\
& Rolling velocity $/(\mathrm{mm} \cdot \mathrm{s}-1)$ & 7000 \\
Roll Young's modulus/MPa & 206000 \\
Poisson ratio & 0.3 \\
Density/tonne $\cdot \mathrm{mm} 3$ & $7.8 \times 10-9$ \\
\hline
\end{tabular}

The 11th International Conference on Numerical Methods in Industrial Forming Processes AIP Conf. Proc. 1532, 478-483 (2013); doi: 10.1063/1.4806864

(C) 2013 AIP Publishing LLC 978-0-7354-1156-2/\$30.00 


\begin{tabular}{lll}
\hline Foil & Entry foil thickness/mm & 0.1 \\
& Reduction/\% & 50 \\
& Young's modulus/MPa & 68000 \\
Density/tonne $\cdot \mathrm{mm} 3$ & $2.7 \times 10-9$ \\
Poisson ratio & 0.34 \\
\hline
\end{tabular}

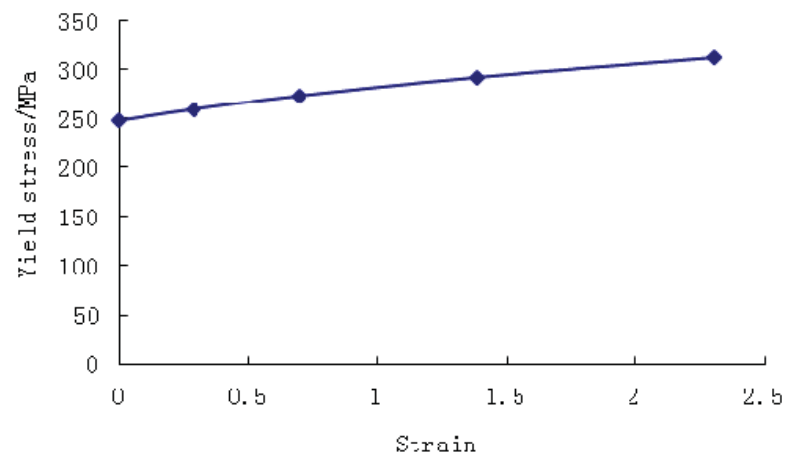

FIGURE 1. Yield Stress-strain Curve of Foil

Upper work roll is modeled as an elastic body whereas upper half foil is modeled as an elasto-plastic body. Considering that thickness of foil is very thin, an extremely fine discretization of the work roll sleeve near the contact region is essential to obtain reliable data. A value of $100 \mu \mathrm{m}$ has been chosen for work roll element length in contact surface. The corresponding foil surface element is less than $50 \mu \mathrm{m}$. The friction between the foil surface and work roll surface is modeled by utilizing the coulomb friction law with a friction value of 0.05 . Explicit dynamic algorithms are chosen for this case. The mesh generation of model is shown in FIGURE2 (a). Transition between coarse and fine meshed region is given in FIGURE 2 (b).

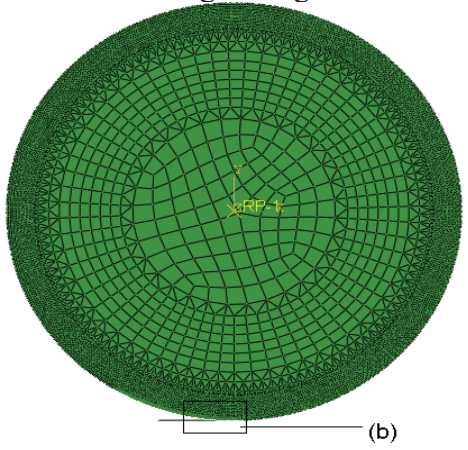

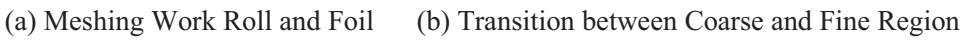

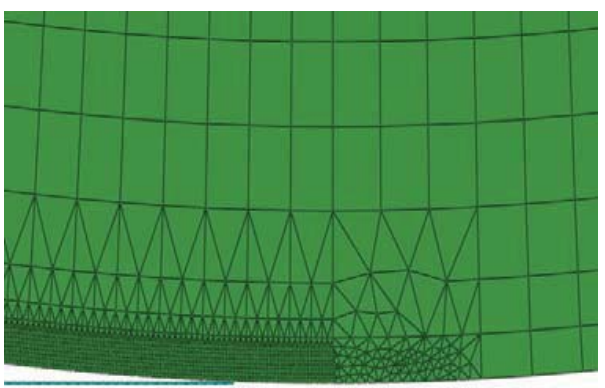

FIGURE 2. Mesh Generation of the Model 


\section{NUMERICAL RESULTS}

\section{Contact Pressure and Roll Contour in Roll Bite}

By using parameters in TABLE (1), the Mises stress distribution inside the foil and work roll in steady state is demonstrated in FIGURE 3.

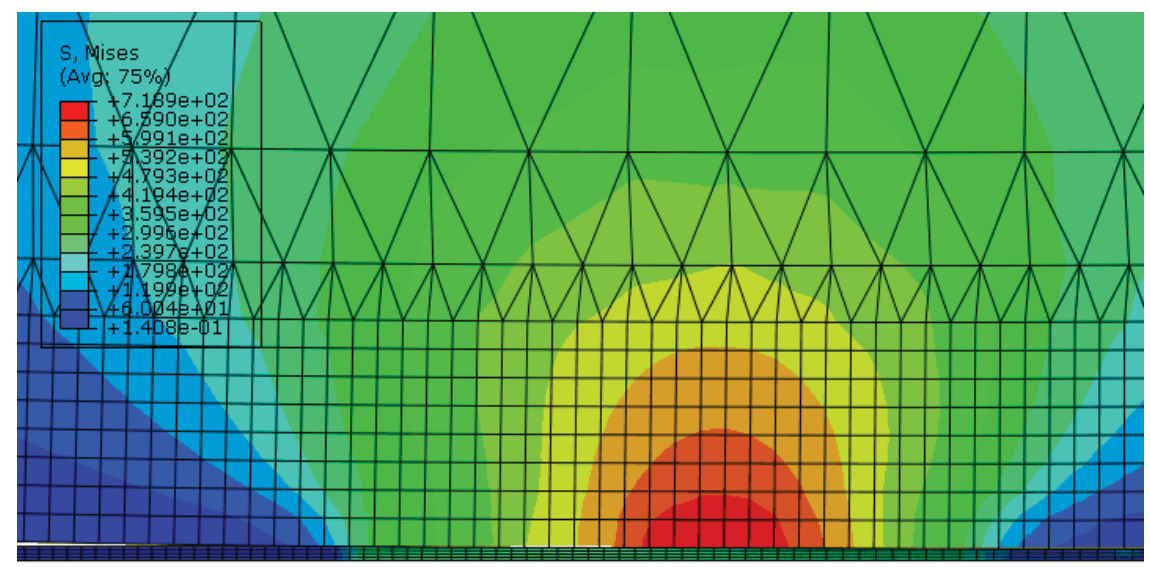

FIGURE 3. Mises Stress Distribution inside the Foil and Work Roll in Steady State

The profile contact surface and contact pressure are shown in FIGURE 4. It should be emphasized that the roll profile in contact area with foil is consistent with contact foil surface because of coupling relationship. A neutral zone of finite length, namely a central flattened region exists in roll bite in which contact pressure reaches peak and no slip between foil and roll. It coincides with the results of FLECK et al assumptions about foil rolling. However, entry elastic zone and exit elastic zone are included in this model. In the whole contact arc length, it consists of entry elastic zone (arc length $\mathrm{AB}$ ), entry plastic zone (arc length $\mathrm{BC}$ ), a central flattened zone (arc length $\mathrm{CD}$ ), exit plastic zone (arc length DE) and exit elastic zone (arc length EF). It is clearly seen from FIGURE 4, Entry and exit elastic zone is an obvious proportion part of roll bite.

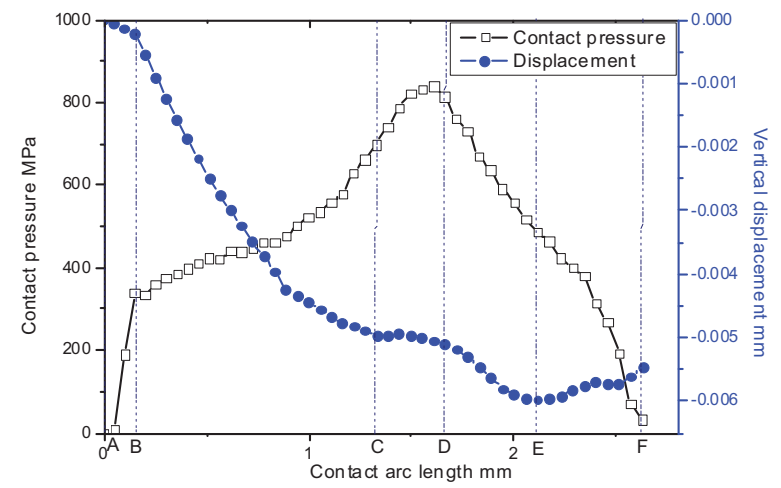

FIGURE 4. Distribution of Contact Surface and Vertical Foil Displacement 


\section{Effect of Entry Thickness on Behaviors in Roll Bite}

In order to investigate the effect of entry foil thickness on behaviors in roll bite, a set of four groups from (a) entry thickness $0.2 \mathrm{~mm}$ to $(\mathrm{d}) 0.04 \mathrm{~mm}$ are presented in FIIIGURE 5. Other rolling parameters, such as reduction rate, rolling speed and friction coefficient are held constant.

In FIGURE 5 (a), the roll profile at contact surface is approximate to be circular arc. Slip occurs through the whole roll bite except at the neutral section where contact pressure reaches peak, which satisfies Bland and Ford rolling theory.

In FIGURE 5 (b), the roll profile at contact surface is to be non-circular and contact pressure becomes sharper. A neutral zone exists in roll bite where no slip occurs.

In FIGURE 5 (c) and (d), with the decrease of entry thickness, the proportion of neutral zone for the whole roll bite increases. Entry plastic reduction occurs in shorter zone whereas exit plastic reduction occurs in relative longer zone.

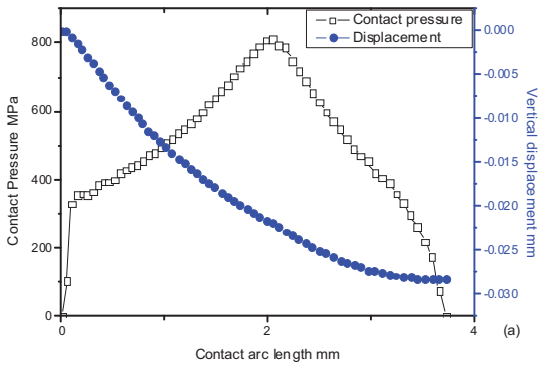

(a) Entry thickness $0.2 \mathrm{~mm}$

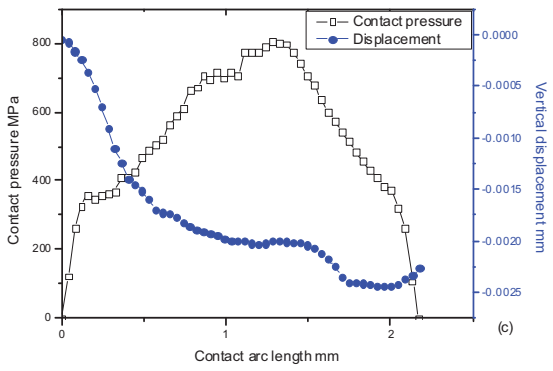

(c) Entry thickness $0.08 \mathrm{~mm}$

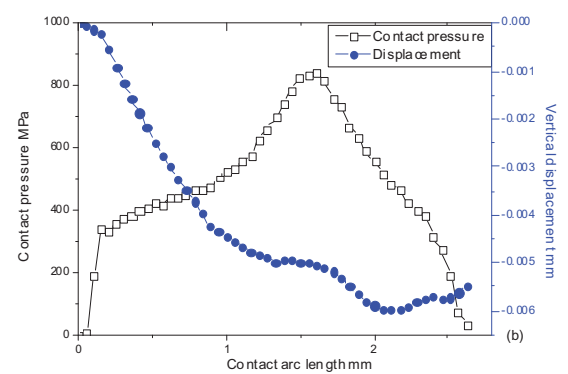

(b) Entry thickness $0.1 \mathrm{~mm}$

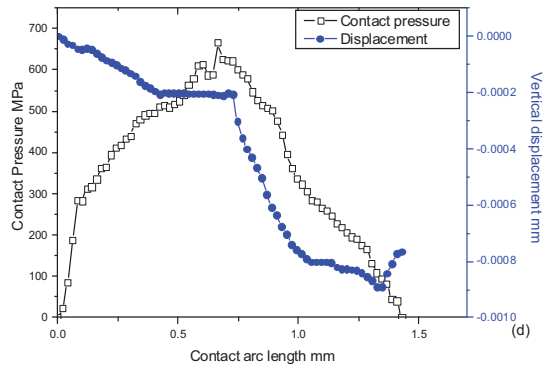

(d) Entry thickness $0.04 \mathrm{~mm}$;

FIGURE 5 Effect of Entry Thickness on Distribution of Contact Pressure and Vertical Displacement.

\section{Effect of Friction Coefficient on Behaviors in Roll Bite}

The friction between the work roll and the foil is a key parameter in cold rolling process [10-12]. The values of the friction coefficient may change significantly at different stages of rolling and also has significant effect on the distribution of contact force and work roll flattens. With rolling parameters in TABLE 1 and other two friction coefficient 0.03 and 0.07, distribution of contact pressure and vertical displacement are shown in FIGURE 6. 

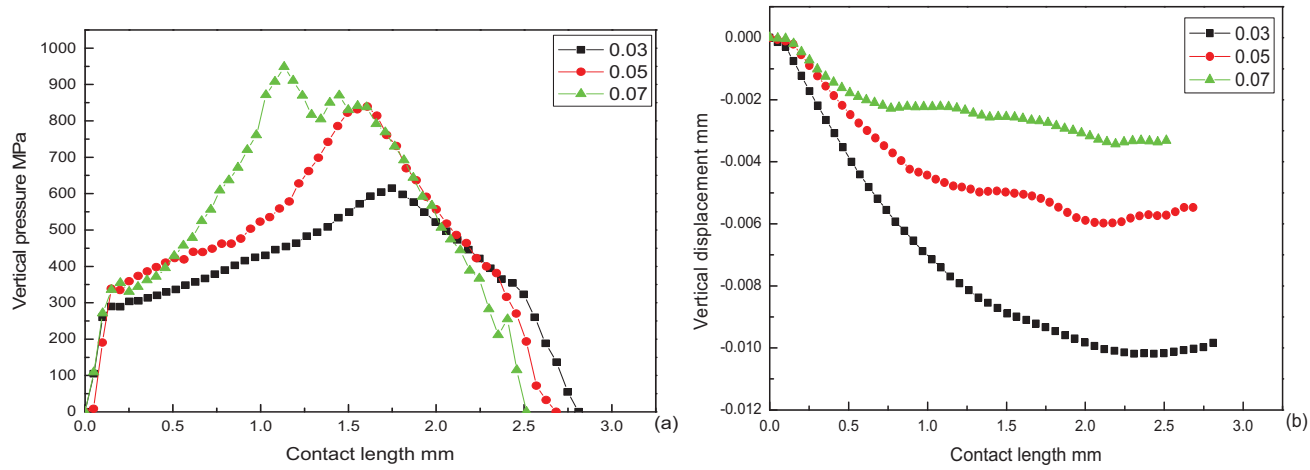

FIGURE 6 Effect of Friction Coefficient on Behaviors in Roll Bite.

(a) Contact Pressure Distribution; (b) Vertical Displacement Distribution

In FIGURE 6, it is shown that friction coefficients have great influenced on contact pressure and vertical displacement. With the increase of friction coefficient, Contact arc length reduces and contact pressure peak moves to entry side. When the friction coefficient is 0.03 , the contact arc is nearly circular; but non-circular with neutral zone appears under 0.05 and 0.07 coefficients. Vertical displacement reduces obviously whereas neutral zone increases when the friction coefficient increases.

\section{Effect of reduction rate on Behaviors in Roll Bite}

Rolling parameters in TABLE 1 and other two different reductions rates, $10 \%$ and 30\% are applied to simulate respectively.
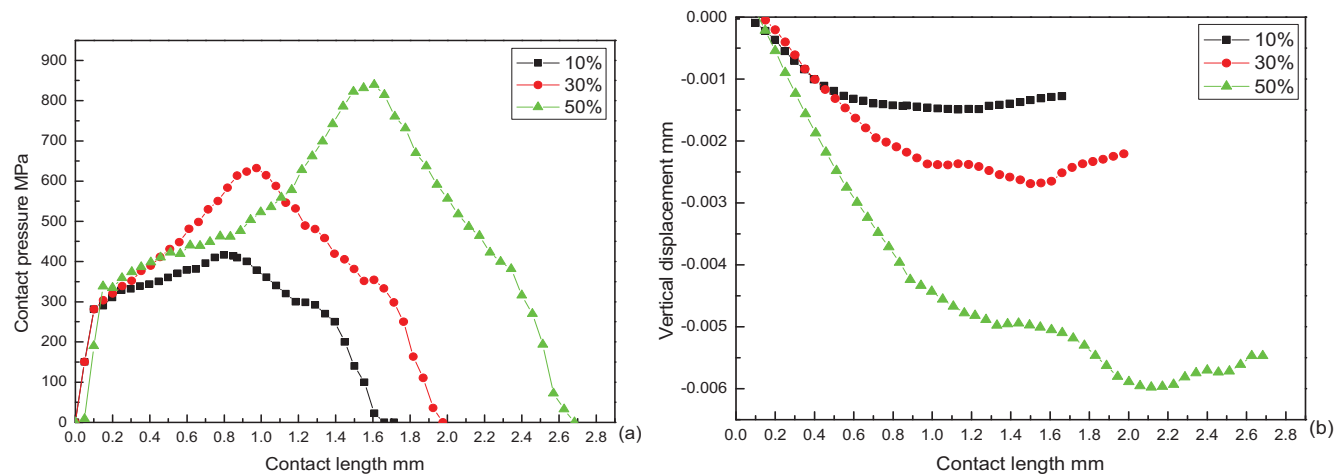

FIGURE 7. Effect of Reduction Rate on Behaviors in Roll Bite.

(a) Contact Pressure Distribution; (b) Vertical Displacement Distribution

FIGURE 7(a) shows the effect of reduction rate on distribution of contact pressure. It can be seen that contact arc length becomes longer and 'pressure distribution hill' gets sharper as the reduction rate increases. FIGURE 7 (b), when the reduction rate is $10 \%$, the contact arc profile is nearly circular. It changes to be non-circular with $30 \%$ and $50 \%$ reduction rate. Length of neutral zone at $50 \%$ is greater than that of $30 \%$.

\section{CONCLUSIONS}

(1) A 2D elasto-plastic finite model is developed to simulate foil rolling process. The results prove the prediction of Fleck et al about cold foil rolling. Entry and exit elastic deformation zone are also include in this model. An extensive neutral zone exists in foil rolling 
(2) Effect of entry thickness on behaviors in roll bite is discussed. Roll contact profile is approximate to be circular arc with $0.2 \mathrm{~mm}$ entry thickness. With the decrease of entry foil thickness, contact arc profile changes to be non-circular and the proportion of neutral zone for the whole roll bite increases. Entry plastic reduction occurs in shorter zone whereas exit plastic reduction occurs in relative longer zone.

(3) Contact arc length reduces and contact pressure peak moves to entry side when the friction coefficient increases. The contact arc is nearly circular at 0.03 friction coefficient; but non-circular with neutral zone appears under 0.05 and 0.07 coefficients. Vertical displacement reduces obviously whereas neutral zone increases when the friction coefficient increases

(4) As the reduction rate increases, 'contact pressure distribution hill' gets sharper; contact arc length and neutral zone become longer.

\section{ACKNOWLEDGMENTS}

Special tribute should be paid to Dr Yiping SHI for his assistance on finite element method simulation process and Dr Remn min GUO for his valuable advice on thin strip rolling theory.

\section{REFERENCES}

1. N.A. FLECK and K.L. JOHSON, International Journal of Mechanical Sciences29(7), 507-524(1987).

2. Fleck NA, Johnson KL et al., Proceedings of the Institution of Mechanical Engineers206, 120-121(1992).

3. Johnson KL, Contact mechanics, Cambridge: Cambridge University Press, 1985.

4. L. C. ZHANG., Int. J. Mech. Tools Manufact 35(3), 363-372(1995).

5. H.R. Le, and M.P.F. Sutclifffe., Internal Journal of Mechanical Sciences43 (6), 1405-1419(2001).

6. Sutcliffe MPF, Rayner PJ., International Journal of Material Sciences40(9), 887-888(1998).

7. T.A.M. Langland et al., International Journal of Mechanical Sciences46, 1139-1156(2004).

8. Domanti SA, Edwards WJ, Thomas PJ., AISE Annual Convection. Ohio, USA: Cleveland, 1994.

9. Abaqus Standard, Explicit, CAE/V6.9, Hibbitt, Karlsson \& Sorensen, Inc., 1080 Main Street, Pawtucket, Rhode Island, USA.

10. A Curnier., International journal of Solids \& Structures20 (7), 637-647(1984).

11. Alfred Zmitrowicz., Wear114 (2), 35-36(1987).

12. C.Canudas de Wit, H, Olsson et al., IEEE TRANSACTIONS ON AUTOMATIC XONTROL40(3), 1995. 